\title{
Dos cuartetos de Joseph Haydn para el Duque de Alba ${ }^{1}$
}

\author{
Two Quartets of Joseph Haydn for the DUKe of ALBa
}

Stephanie Klauk

Universität des Saarlandes, Saarbrücken (Alemania)

\section{Resumen:}

De las relaciones que Haydn mantuvo con la nobleza española de su tiempo destaca el contacto con la Condesa-Duquesa de Benavente. Mediante contrato, Haydn se comprometió a mandar a la Condesa cada año alrededor de doce composiciones nuevas. Aunque no se sabe hasta qué punto cumplió Haydn con su parte del contrato, es bastante probable que hayan llegado algunas obras a España todavía desconocidas o no identificadas.

Un ejemplo prominente es el de los dos cuartetos "destinados para el Excmo. Sr. Duque de Alba", que Haydn había enviado a la Condesa de Benavente a finales de 1784 o a principios de 1785 según una carta de Carlos Alejandro de Lelis, representante de la Condesa en Viena.

Intentamos desenredar las posibles referencias a las obras conocidas de Haydn y las diferentes interpretaciones que conllevan ésta y otras cartas contemporáneas para aclarar la identificación de los dos cuartetos en cuestión.

Palabras clave:

Haydn; cuartetos de cuerda; Duque de Alba; Condesa-Duquesa de Benavente; Artaria; siglo XVIII.

\section{Abstract:}

It is widely known, that Haydn was in contact also with the Spanish nobility. He even established a contract with the Countess-Duchess of Benavente, in which he promised to send her each year about twelve new compositions. Although we don't know if he fulfilled this requirement every year, he probably sent some works to Spain, which remain still unknown or unidentified.

For instance, according to a letter of Carlos Alejandro de Lelis, who was representing the Countess in Vienna, two quartets destined to the Duke of Alba have been sent to the Countess of Benavente at the end of 1784 or at the beginning of 1785 .

In order to shed some light on the problem of identification of these quartets, different interpretations of this and other contemporary letters are brought into discussion.

\section{Keywords:}

Haydn; String Quartets; Duke of Alba; Countess-Duchess of Benavente; Artaria; 18th century.

1 Este artículo se basa en una ponencia presentada en el Congreso internacional "F. J. Haydn (1732-1809) e I. Albéniz (1860-1909): Clasicismo y nacionalismo en la música española” que tuvo lugar el 21 y 22 de noviembre de 2009 en Cádiz. 
Es suficientemente conocido que Haydn estuvo en contacto con la nobleza española de su tiempo. Aparte de la obra encargada para Cádiz, Las siete últimas palabras de Cristo en la cruz, destaca el acuerdo con la Condesa de Benavente. Según el contrato -fechado en 1783, modificado dos años después y vigente hasta por lo menos 1789- Haydn se comprometió a mandar a la Condesa cada año alrededor de doce composiciones ${ }^{2}$. No se sabe en qué medida cumplió Haydn con su parte del contrato. Es de suponer que las obras enviadas no llegaron a lo convenido inicialmente, ya que la propia Condesa se conformó con menos ${ }^{3}$. Aún así, es bastante probable que hubieran llegado algunas obras a España que (todavía) sean desconocidas o no estén identificadas.

Un ejemplo prominente es el de los dos cuartetos "destinados para el Excmo. Sr. Duque de Alba", que Haydn había enviado a la Condesa de Benavente a finales de 1784 o principios de 1785. Así lo leemos en la famosa carta que Carlos Alejandro de Lelis -representante de la Condesa en Viena- dirige a Tomás de Iriarte -escritor y hombre de confianza de la Condesa- el 24 de marzo de 1785:

"Mur[sic] Sr. mío y amigo de mi mayor estimación: Antes de todo debo pedir a Vm. perdón por haber dejado pasar tanto tiempo sin satisfacer a mi promesa y pedirle se sirva atribuir esta tardanza no a defecto de buena voluntad sino a falta de tiempo.

Ha estado (como creo haber dicho a Vm. en mi última) Haydn en Viena; tuve ocasión de tratar con él largamente sobre el asunto, y para enterarle por menor del contenido de la Carta de Vm. se la traduje en buen alemán. Sintió mucho Haydn de que ni Vm. ni mi Sra. la Condesa de Benavente estuviesen contentos de su conducta, cuando se lisonjeaba de haber satisfecho puntualmente a la Contrata en la cual promete de comunicar no por lo menos 12 piezas de música al año, sino incirca 12 pezze: no sinfonías y cuartetos solos sino toda la música libre que compusiera en el discurso del año, y que por consiguiente podían ser en un año 9, 10, 11, y al otro 18, 20 (porque la prometió toda) según lo más o menos que su amo le daría que hacer en su capilla, o según la calidad de la música que le mandaría componer. Añadió que envió las misas porque yo le había manifestado que las deseaban, y porque creyó poder agradar si las dejaba entrar en cuenta de la Contrata sin hacerlas pagar separadamente, y porque ya naturalmente debían comprenderse bajo la palabra toda la música. Que lo mismo le movió a enviar dos cuartetos, los cuales ya estaban destinados para el Excmo. Sr. Duque de Alba que tanto los había solicitado por el espacio de dos años consecutivos, y pagado la misma suma por otros dos; pero que si todavía no se habían hecho grabar o distribuir copias de ellos, de modo que él los pueda hacer grabar aquí o donde quiera por su cuenta, no tiene reparo en que vayan en cuenta del año pasado; en cuyo caso me devolverá el dinero percibido por ellos. Que no creyó que la circunstancia de faltar a los duetos susodichos los instrumentos de viento que Vm. dice, pudiese hacerlos desagradar, y que no lo había compuesto

2 Álvarez Solar-Quintes, Nicolás: "Las relaciones de Haydn con la Casa de Benavente”, en Anuario Musical, 2 (1947), pp. 82-83.

3 Ibíd., p. 84. 
con ellos porque no gusta trabajar con instrumentos que no son de su facultad, y en cuya especie de composición no sobresale. [...]

Fundaba yo mi esperanza de que Vm. estuviesen medianamente contentos de la remesa que en el año pasado les hice de obras de Haydn (ya que me bastó mi eficacia para lograr más) sobre la expresión de la Contrata que decía in circa pezze dodeci, y en que Vm. mismo se hacía cargo en la referida carta de la semi-imposibilidad que aquel autor cumpliese por entero su Contrata, diciendo: 'No concebimos cómo podrá tener Haydn tiempo y cabeza para desempeñar tanto como ofrece; y nos contentaremos con que cumpla con la mitad'.

He aceptado finalmente los dos Cuartetos con la condición de pagárselos aparte porque Vm. me dijo en la misma carta: 'Desde luego encargue Vm. a Haydn componga para uso privado de S. E. un juego de Cuartetos para violín, oboe, tromba y violoncello', pero confieso al mismo tiempo que no hice alto en que faltaban los instrumentos de viento [...]"4.

Aunque en tiempos de Haydn el término 'cuarteto' era todavía más generalizado y no se limitaba solamente al cuarteto de cuerda, veremos que aquí sí es el caso.

Pero ¿de qué cuartetos de cuerda se trata?

Seguramente no sean dos de los seis cuartetos del opus 33 -compuestos en 1781 y publicados un año después- como supone recientemente Juan Pablo Fernández-Cortés ${ }^{5}$. En 1784, Haydn está trabajando en otra serie de cuartetos. Así lo dice él mismo en una carta al editor vienés Artaria, fechada el 5 de abril de aquel año:

"Wohl gebohrner, hochzuverehrender Herr!

ohngeachtet ich jedes mahl durch meine quartetten mit der Prenumeration mehr dan 100 Ducaten erhielte, und welche mir auch Herr Willmann zu geben versprache, willige ich in die zugesagte $300 \mathrm{fl}$ mit folgender ausnahme ein, erstens daß Sie in geduld stehen bis Ende Juli, jedoch sollen alle Sechs bis dahin verfertiget seyn, zweytens verlange ich entweder 12 Exemplair, oder eine willckhürliche Dedication, soll Ihnen dieser Vertrag anstendig seyn, so Erwarte ich den aufsatz d. Contractes: jene quartetten so ich dermahlen in der arbeith habe, und die helffte fertig, sind ganz klein, und nur mit 3 Stuck, sie gehören nach spanien. Mit nächstem Posttag werd ich Ihnen etwas gedrucktes und zwar eine Zergliederung meiner Cantate, so Sie haben stechen lassen, mit einem ungemeinen Beyfall übermachen, so mir Herr Professor Cramer aus Kiel nebst einem schreiben zuschückte. Leben Sie unterdessen wohl. Ich bin in Eyl"'.

4 Álvarez Solar-Quintes, Nicolás: “Las relaciones de Haydn con la Casa de Benavente”, en Anuario Musical, 2 (1947), pp. 82-84.

5 Fernández-Cortés, Juan Pablo: La música en las casas de Osuna y Benavente (1733-1882): un estudio sobre el mecenazgo musical de la alta nobleza española. Madrid, Sociedad Española de Musicología, 2007, p. 377.

6 Bartha, Dénes (ed.): Joseph Haydn: Gesammelte Briefe und Aufzeichnungen: unter Benützung der Quellensammlung von H. C. Robbins Landon. Kassel, Bärenreiter, 1965, p. 136. Traducción propia:

"Muy Señor mío! 
Haydn menciona que está componiendo unos cuartetos 'destinados a España'. Como dice además que la mitad de ellos ya están terminados, resulta más probable que sean estos cuartetos del año 1784 los que efectivamente mandó unos meses después a España: hay razones para suponer que fueron enviados en primer lugar al Duque de Alba, aunque no tenemos constancia de ello ${ }^{7}$; pero si podemos asegurar que la Condesa-Duquesa de Benavente los recibió ${ }^{8}$.

¿Conocemos estos cuartetos hoy en día o están perdidos o no identificados?

Dado que en el tiempo transcurrido entre el opus 33 y el opus 42 no se conocen otros cuartetos de Haydn, la mayoría de los musicólogos han intentado relacionar los mencionados cuartetos de la carta a Artaria con el cuarteto suelto del opus 42, publicado en 1786 por Hoffmeister: así lo hizo Ludwig Finscher en la obra Joseph Haydn und seine Zeit en el año 2000'.

Referente a los cuartetos en cuestión, atribuye a la palabra 'pequeño' el significado de 'corto'. Comparándo el número de compases, el cuarteto del opus 42 de hecho es pequeño: tiene apenas 300 compases, mientras que los cuartetos del opus 33 y los del opus 50 comprenden entre 378 y 664 compases. Un aspecto que concuerda menos es la interpretación de la expresión 'tres piezas' en el sentido de tres movimientos, porque implicaría que Haydn hubiese añadido finalmente un cuarto movimiento -como lo tiene el opus 42. De los habitualmente seis cuartetos se hubiesen perdido entonces cinco o, si suponemos que no componía más de la mitad que tenía ya en el momento de escribir la carta, por lo menos dos cuartetos.

Floyd y Margaret Grave en su libro The String Quartets of Joseph Haydn (2006) resumen de esta manera: "We learn simply that a group of three quartets has been requested by someone in Spain [...], that the works are 'very short', that each consists of three movements, and that the project is half completed" 10.

Evidentemente es un malentendido, ya que la indicación 'tres piezas' no se puede referir al mismo tiempo al número de cuartetos y al número de movimientos ${ }^{11}$. Si Haydn se refiere solamente al número de cuartetos, habla de otra serie de cuartetos -seis- al principio de la carta.

aunque recibiera por mis cuartetos con la prenumeración cada vez más de 100 ducados, y los que me prometió además el Señor Willmann, estoy conforme con los 300 florines prometidos con la excepción siguiente, primero que Usted tenga paciencia hasta finales de julio, pero que todos los seis deberían estar terminados entonces, segundo quiero obtener o 12 ejemplares o una dedicación libre, si Usted esté conforme con este contrato, espero su redacción: aquellos cuartetos en los que estoy trabajando, y la mitad terminados, son muy pequeños y con solamente tres piezas, son destinados a España. El siguiente día laboral le remitiré algo imprimido, con crédito extraordinario, una disección de mi cantata, la que Usted había tallado, que me envió el Señor Profesor Cramer de Kiel con un escrito. Quede Usted con Dios de mientras. Tengo prisa".

7 Por lo visto, hoy en día no se encuentran en el archivo musical de la Duquesa de Alba (véase: SubIRÁ, José: La música en la casa de Alba: estudios históricos y biográficos. Madrid, s.n., 1927), pero si no los hubiese recibido el Duque de Alba entonces, seguramente no le habría pagado a Haydn "la misma suma por otros dos" (Álvarez Solar-Quintes, Nicolás: "Las relaciones de Haydn con la Casa de Benavente", en Anuario Musical, 2 [1947], p. 83).

8 Aparte de su mención en la carta de Alejandro de Lelis, podrían ser los mismos dos cuartetos sueltos de Haydn que se encuentran en el índice de la biblioteca musical de la Duquesa Condesa de Benavente del año 1824 (FERNÁNDEZ-CoRTÉs, Juan Pablo: La música en las casas de Osuna y Benavente [1733-1882]: un estudio sobre el mecenazgo musical de la alta nobleza española. Madrid, Sociedad Española de Musicología, 2007, p. 444).

9 Finscher, Ludwig: Joseph Haydn und seine Zeit. Laaber, Laaber-Verlag, 2000, p. 412.

10 Grave, Floyd y Margaret: The String Quartets of Joseph Haydn. Nueva York, Oxford, Oxford University Press, 2006, p. 218.

11 De hecho, la expresión 'tres piezas' siempre ha sido interpretada o de una o de otra manera. En el sentido de tres cuartetos por ejemplo en Keller, Hans: The Great Haydn Quartets. Their Interpretation. Nueva York, George Braziller, 1986, p. 82; en el sentido de tres movimientos por ejemplo en FEDER, Georg: "Die Überlieferung und Verbreitung der handschriftlichen Quellen zu Haydns Werken", en Haydn-Studien, 1 (1965), p. 42 y, referiéndose a Feder, también en Stevenson, Robert: "Los contactos de Haydn con el mundo ibérico", en Revista Musical Chilena, 36 (1982), p. 18. 
Recordemos que la siguiente serie publicada, el opus 50, se menciona por primera vez también en una carta a Artaria en febrero de $1787^{12}$. ¿Podría ser, entonces, que Haydn no hubiera terminado los seis cuartetos mencionados en su carta al editor del 5 de abril de 1784 hasta tres años después? ¿O no llegó antes a ningún acuerdo con Artaria en lo que respecta a las modificaciones de un nuevo contrato?

Intentamos desenredar las diferentes posibilidades concordándolas sobre todo con las indicaciones de las dos cartas.

Es bastante probable que el cuarteto del opus 42 sea parte de los mencionados cuartetos "muy pequeños" y "destinados a España"; no solamente por el número de compases, sino también porque difiere estilísticamente de los anteriores y posteriores cuartetos. Falta el nombre del destinatario, pero de la carta de Alejandro de Lelis podemos deducir que, en un principio, no era la Condesa de Benavente, sino el Duque de Alba "que tanto los había solicitado por el espacio de dos años consecutivos, y pagado la misma suma por otros dos". Es decir, que el Duque de Alba le encomendó a Haydn la composición de por lo menos dos cuartetos ya por el año 1783. Por el contrato con la Condesa, sin embargo, Haydn solamente tenía la obligación de enviarle alrededor de doce composiciones al año, independientemente del género musical. Parece más bien que Haydn quería aprovechar los dos cuartetos para contentar tanto al Duque de Alba que a la Condesa de Benavente ${ }^{13}$, ya que ésta en un principio no había solicitado un cuarteto de cuerdas, sino un juego para violín, oboe, tromba y violoncello ${ }^{14}$.

Quizás así, se podría explicar la expresión ‘tres piezas' para España: dos cuartetos para el Duque de Alba y uno para la Condesa. Quedaría la pregunta, si el cuarteto del opus 42 es uno de los dos enviados u otro tercero. No se ha encontrado el autógrafo del opus 42 y la única copia manuscrita data del año $1785^{15}$. La publicación por Hoffmeister se realizó en 1786, así que las fechas concordarían con la declaración de Haydn en 1785 que "todavía no se habían hecho grabar o distribuir copias de ellos"16. Si nos inclinamos a esta interpretación, faltarían por lo menos dos autógrafos y nos sería desconocido como mínimo un cuarteto entero.

Tampoco se conocen los autógrafos de los dos primeros cuartetos del opus 50. Pero si estos fueran los dos cuartetos mandados a España, Haydn no se hubiese aprovechado económicamente del único cuarteto 'pequeño' (y tal vez otro sin terminar) hasta su publicación dos años después.

Aunque no se puedan aclarar todas las incertidumbres, independientemente de la interpretación favorecida, lo que sí es evidente es la ausencia de autógrafos o cuartetos completos; una ausencia que con la mayor probabilidad es una consecuencia de los contratos exclusivos entre Haydn y la nobleza española.

Recibido: 30/11/2010

Aceptado: 03/06/2011

12 Bartha, Dénes (ed.): Joseph Haydn: Gesammelte Briefe und Aufzeichnungen: unter Benützung der Quellensammlung von H. C. Robbins Landon. Kassel, Bärenreiter, 1965, p. 157.

13 Véase también FedER, Georg: "Die Überlieferung und Verbreitung der handschriftlichen Quellen zu Haydns Werken", en Haydn-Studien, 1 (1965), p. 42.

14 ÁlvareZ Solar-Quintes, Nicolás: “Las relaciones de Haydn con la Casa de Benavente”, en Anuario Musical, 2 (1947), p. 84.

15 Véase Feder, Georg: "Joseph Haydn", en Die Musik in Geschichte und Gegenwart. 2a edición. "Personenteil 8". Kassel, Bärenreiter, 2002, col. 1011 .

16 Álvarez Solar-Quintes, Nicolás: “Las relaciones de Haydn con la Casa de Benavente”, en Anuario Musical, 2 (1947), p. 83. 
